\title{
Diretrizes de implementação para Sistemas de Gestão da Qualidade em instituições de ensino sob o enfoque da Educação Inclusiva
}

\author{
Implementation Guidelines for the Quality Management System in \\ educational institutions under the focus of Inclusive Educaction
}

Directrices para la implantación de los Sistemas de Gestión de Calidad em escuelas desde la perspectiva de la Educación Inclusiva

Milene Karolyne de Souza

Graduanda na Universidade Federal de Pernambuco, Caruaru, PE, Brasil

E-mail: milenekarolyne@gmail.com ORCID: https://orcid.org/0000-0002-3952-0551

Luciano Pereira da Silva Santos

Graduando na Universidade Federal de Pernambuco, Caruaru, PE, Brasil

E-mail: lucianosspereira88@gmail.com ORCID: https://orcid.org/0000-0002-8560-7877

Renata Maciel de Melo

Professora doutora da Universidade Federal de Pernambuco, Caruaru, PE, Brasil

E-mail: renatamaciel0@gmail.com ORCID: https://orcid.org/0000-0001-9111-9426

Recebido em 12 de maio de 2021

Aprovado em 07 de outubro de 2021

Publicado em 29 de outubro de 2021

\section{RESUMO}

Gestão da Qualidade em instituições de ensino, normas ISO (ISO 9001 e ISO 21001), ferramentas da qualidade e Educação Inclusiva (Lei Brasileira de Inclusão), são temas importantes e que nem sempre são pensados em conjunto. Com o objetivo de preparar as instituições de ensino para receber alunos de forma equitativa, e promover condições igualitárias de acesso e permanência na escola, são necessárias ferramentas que deem suporte ao desenvolvimento de novas abordagens gerenciais. Assim, é preciso desenvolver diretrizes para que a Educação Inclusiva nas instituições de ensinoseja implementada de forma eficiente e eficaz, e para que essas instituições tenham a possibilidade de assegurar o seu funcionamento e garantir que os alunos (com deficiência ou não) estejam realmente recebendo uma educação de qualidade. Os objetivos deste trabalho envolvem: analisar os processos de implementação do Sistema de Gestão da Qualidade em organizações educacionais, e propor um modelo com diretrizes que auxilie a sua execução e manutenção, sob o enfoque da Educação Inclusiva. Para isso, realizou-se um levantamento bibliográfico para entender a situação da Educação Inclusiva no Brasil e levantar os principais problemas no seu processo de implementação. Como resultado, foi desenvolvido um modelo que contempla importantes elementos que precisam ser trabalhados em conjunto, entre leis e ferramentas da qualidade, e cinco diretrizes de implementação foram descritas. Constatou-se que apesar da existência de normas e leis 
http://dx.doi.org/10.5902/1984686X65753

que auxiliam nessa prática, é necessária uma abordagem diferente para auxiliar nos processos internos e sustentar a Educação Inclusiva nas instituições de ensino.

Palavras-chave: Gestão da qualidade em instituições de ensino; NBR ISO 21001; educação inclusiva.

\section{ABSTRACT}

Quality Management in educational institutions, ISO standards (ISO 9001 and ISO 21001), quality tools and Inclusive Education (Lei Brasileira de Inclusão - Brazilian Inclusion Law), are important themes that are not always aligned and thought together. With a focus on preparing and organizing educational institutions to receive all students equitably, and promote equal conditions of access and permanence at school, there must be tools to support the development of new management approaches to these goals. Thus, it is necessary to develop guidelines so that Inclusive Education in educational institutions is implemented efficiently and effectively, and that the educational institution has the possibility to ensure its functioning and guarantee that the students (with or without disabilities) are really receiving a quality education. The objectives of this paper, involve analysing the processes of implementing the Quality Management System in educational organizations and propose a model with guidelines that assist in its execution and maintenance under the focus of Inclusive Education. For this, a bibliographic survey was carried out to understand the situation of Inclusive Education in Brazil, and bring up the main problems in its implementation process. As a result, a model was developed, contemplating important elements that must be addressed together, among laws and quality tools, and five implementation guidelines have been described. The results show that despite the existence of standards and laws that assist this practice, a different approach is needed to assist in internal processes and sustain Inclusive Educational in educational institutions.

Keywords: Quality management in education institutions; NBR ISO 21001; inclusive education.

\section{RESUMEN}

Son importantes temas en las escuelas, la gestión de la calidad, las normas ISO (ISO 9001 y ISO 21001), las herramientas de calidad y la educación inclusiva, pero no siempre estos aspectos son considerados conjuntamente. Con vistas a orientar las escuelas a recibir los alumnos con un trato equitativo, promocionar condiciones de igualdad de acceso, y permanencia en el sistema educativo, son necesarias herramientas para apoyar el desarrollo de nuevos enfoques de gestión. Con esto, se hace necesario desarrollar directrices para que la educación inclusiva sea planteada de manera eficiente y eficaz, y que el sistema educativo pueda asegurar su implementación garantizando que los alumnos (con discapacidad o no) reciban una educación y formación de calidad. Hace parte de los objetivos de este trabajo, analizar los procesos de implementación de los Sistemas de Gestión de Calidad en organizaciones de educación. Y proponer un modelo con directrices que apoye su ejecución y mantenimiento bajo la perspectiva de la educación inclusiva. Para ello, se hizo una revisión bibliográfica con vistas a comprender el contexto de la educación inclusiva en Brasil, y dar a conocer los problemas más representativos en su proceso de 
implementación. El resultado ha sido un modelo que contempla importantes elementos que se deben trabajar concomitantemente, entre leyes y herramientas de calidad, a parte de que se han descrito, cinco directrices de implementación para el logro de la educación inclusiva. Se ha constatado, además, que pese la existencia de marco legal sobre el tema, se hace necesario un enfoque distinto para ayudar en los procesos internos, para sostener la Educación Inclusiva en las instituciones educativas.

Palabras clave: Gestión de calidad em escuelas; NBR ISO 21001; educaión inclusiva.

\section{Introdução}

Há algumas décadas, a Educação Inclusiva faz parte dos debates educacionais no Brasil, e a discussão acerca da Educação Inclusiva de qualidade envolve não somente a aceitação de alunos com deficiência no ambiente regular das salas de aula, como também a mudança nas atribuições das intituições educacionais, e a transformação das relações no ambiente escolar. Essa transformação é necessária para fortalecer o sentimento de inclusão desses alunos no contexto social, e escolar, além de possibilitar a integração com os demais estudantes. E não só isso, mas um acompanhamento especializado deve ser ofertado para que esses alunos possam aprender e se desenvolver de acordo com as suas necessidades.

Tanto no Brasil quanto em outros países do redor do mundo foram consolidadas convenções e leis no que diz respeito à educação para todos. Aqui no Brasil, por exemplo, a Lei Brasileira de Inclusão da Pessoa com Deficiência, também conhecida por Estatuto da Pessoa com Deficiência, exerce forte influência. Ademais, há grandes referências internacionais como a Declaração de Salamanca (1994), Declarações da UNESCO, Declaração Mundial de Educação para Todos (1990 e a Convenção sobre os Direitos das Pessoas com Deficiência (2006). Há, também, normas da ISO (International Organization for Standardization), as quais mencionam a educação para todos os alunos de forma inclusiva, como por exemplo a ISO 21001 (Organizações Educacionais - Sistema de Gestão para Organizações Educacionais).

Entretanto, mesmo com diversas convenções e algumas normas que auxiliam os usuários, ainda há certo grau de dificuldade na efetivação da Educação Inclusiva. Entre as principais dificuldades listadas, aparecem a falta ou a formação insuficiente dos professores para lidar com alunos com deficiência, falta de comprometimento da alta gerência em acompanhar o processo e escassez de recursos (sejam materiais didáticos, metodologias, planos de ação ou infraestrutura). 
http://dx.doi.org/10.5902/1984686X65753

Nesse sentido, fica claro que há necessidade de desenvolver, não uma nova metodologia para que a Educação Inclusiva nas instituições de ensino seja implantada, mas, sim, um plano de ação para que, após ser inserida a prática inclusiva, a instituição de ensino tenha possibilidade de assegurar o seu funcionamento e garantir que os alunos beneficiados estejam, realmente, recebendo uma educação de qualidade.

Observadas essas necessidades, esse trabalho buscou levantar e verificar os principais problemas do processo de implementação da Educação Inclusiva nas instituições de ensino, bem como realizou um alinhamento dos temas Gestão da Qualidade e Educação Inclusiva. E, por conseguinte, promoveu o desenvolvimento de um modelo de Gestão da Qualidade com enfoque na Educação Inclusiva.

\section{Educação Inclusiva}

Quando o termo Educação Inclusiva é abordado, muitas pessoas remetem ao conceito de Educação Especial. A Educação Especial é uma modalidade de ensino voltada para os alunos com alguma deficiência, e visa a identificar as barreiras que dificultam o acesso do aluno ao currículo escolar. Já a Educação Inclusiva envolve o conceito de educação pensada para todos, ligada a medidas adotadas para pessoas com deficiência, com o intuito de inserilas no âmbito escolar. Dessa forma, a Educação Inclusiva possibilita que pessoas com deficiência possam interagir, no mesmo espaço educacional, com pessoas que não têm deficiência, e, assim, todos terão possibilidade de aprender e de se formar, levando em conta as peculiaridades de cada indivíduo, e no devido tempo.

É valido salientar que cada país tem suas leis para tratar do assunto da Educação Inclusiva com perspectiva da deficiência. Algumas nações se inspiram em grandes convenções sobre o tema, como a Declaração de Salamanca e a convenção da própria Unesco.

Além disso, em âmbito mundial, há várias ações em prol da Educação Inclusiva, tais como, segundo Amor et al. (2018): A Declaração Mundial de Educação para Todos (1990), Declaração de Dakar (2000), Convenção sobre os Direitos das Pessoas com Deficiência (2006), além da própria Declaração de Salamanca, entre outras declarações e quadros que objetivam a educação para todos. Dessa forma, fica claro que todos os países envolvidos nesses eventos demonstram grande preocupação no quesito de integração desse público, isso é, de fato existem movimentações para esse tipo de educação ao redor do mundo. 
http://dx.doi.org/10.5902/1984686X65753

Segundo o registro de Ferguson (2008), o início da educação especial com foco na inclusão aconteceu nos Estados Unidos e na Europa. De fato, pode-se observar que foram justamente nessas nações que ocorreram tais eventos importantes para a conscientização sobre as pessoas com deficiência.

No Brasil, a Câmara de Educação Básica (CEB) do Conselho Nacional da Educação (CNE), estabeleceu o público alvo para o Atendimento Educacional Especializado (AEE) na Resolução CNE/CEB n 4 de 2009: Alunos com deficiência, alunos com transtornos globais do desenvolvimento e alunos com altas habilidades/superdotação.

Em 2015, foi aprovada a Lei 13.146/2015, a Lei Brasileira de Inclusão da Pessoa com Deficiência, também conhecida como Estatuto da Pessoa com Deficiência, que tem o objetivo de assegurar as condições de igualdade para pessoas com deficiências almejando a sua inclusão social e cidadania, como relatado no seu artigo primeiro.

\section{Cenário atual}

Segundo Santana e Nunes (2018), a Educação Inclusiva no território brasileiro é algo bastante contemporâneo e de abordagem recente, mas que abrange avanços significativos, tanto em questões político-legais quanto nas questões práticas. Sabe-se que esse avanço aconteceu de forma gradativa, isso é, à medida que iam surgindo novas legislações voltadas para a inclusão, as políticas de implantação eram postas em prática.

É preciso salientar, também, que a Lei 9394/96, Lei de Diretrizes e Bases da Educação Nacional (LDB), é considerada como o marco para o reconhecimento da Educação Especial como uma política voltada para as assertividades da educação (SILVA et. al., 2019).

Outro marco importante foi a Política Nacional de Educação Especial na Perspectiva da Educação Inclusiva - PNEEPEI, de 2008, que em seu texto-base objetivava o acesso, a participação e a aprendizagem de alunos com deficiência, transtornos globais de desenvolvimento e altas habilidades/superdotação nas escolas regulares, prevendo a preparação de professores e outros profissionais de educação para o atendimento educacional especializado e inclusão escolar (BRASIL, 2008).

Dados do Censo Escolar/MEC/INEP de 2019, demonstram que o percentual de alunos com deficiências, autismo ou altas habilidades matriculados em classes comuns, tem aumentado gradualmente para todas as etapas de ensino (INEP, 2021). Comprovando-se, assim, os impactos positivos gerados pela implementação de políticas legais dessa natureza ao longo do tempo. 
http://dx.doi.org/10.5902/1984686X65753

No entanto, esse cenário pode estar sendo distorcido com a exclusão interna dos alunos. Isso significa que, de fato, os alunos com algum tipo de deficiência têm acesso às escolas, porém, essa prática é confundida com a de agregar, e não de incluir, esses estudantes nas atividades educacionais. Em outras palavras, os indivíduos vão à escola, mas não participam de atividades escolares, planos pedagógicos de ensino ou acompanhamento, não desenvolvem as habilidades desejadas, causando, dentre outros prejuízos, a frustração e, consequentemente, desistência da tentativa de inserção no contexto escolar em decorrência da ineficiência do planejamento.

Um estudo sobre o ingresso e a permanência de universitários com deficiências de Urban (2016), aponta que, apesar de os alunos estarem inseridos nas Instituições de Ensino Superior (IES) e de ações realizadas pelas diferentes esferas das IES, esses alunos ainda encontram barreiras para efetivar a sua permanência, e precisam de apoio durante o ingresso e toda a sua jornada acadêmica. De acordo com Fantacini e Almeida (2019, p.18), ainda que o acesso seja garantido, as IES precisam se preparar para acolher e garantir a permanência desse estudante, que era excluído dessa modalidade de ensino até pouco tempo.

A nova Política Nacional de Educação _PNEE, instituída pelo Decreto nº 10.502, de 30 de setembro de 2020, no intuito de delegar à família o poder de escolha quanto à melhor alternativa educacional em cada caso, instituiu como opções de ambientes escolares as escolas regulares inclusivas, as escolas especializadas e as escolas bilíngues de surdos (BRASIL, 2020). A possibilidade de separar alunos com deficiência daqueles que não possuem deficiência pode ser encarada, de certa forma, como uma barreira para inclusão, anteriormente superada na adoção de outras políticas. A Educação Inclusiva no Brasil continua enfrentando obstáculos, e eles devem ser superados para atingir melhores resultados.

\section{Barreiras e desafios da prática da Educação Inclusiva}

A Educação Inclusiva é uma realidade cada vez mais presente no cotidiano das escolares regulares, desafiando educadores, colaboradores envolvidos no processo da educação, pais e os próprios alunos com deficiência. De acordo com Glat et al. (2006, p.13) "o professor, sozinho, não faz a inclusão. A política sozinha, não faz a inclusão", e, partindo desse pressuposto, fica evidente que são necessárias ações conjuntas para garantir o ingresso, a permanência e o desenvolvimento desses alunos no processo de ensino- 
http://dx.doi.org/10.5902/1984686X65753

aprendizagem, para que esse ocorra de maneira apropriada e em condições adequadas no ambiente escolar.

Mendonça (2013) aponta como principais barreiras à prática da Educação Inclusiva aquelas que envolvem as atitudes dentro das relações, muitas vezes circundadas por receio e algumas vezes se fundamentado em preconceitos, a acessibilidade, a comunicação, e as barreiras pedagógicas. Já Nozi e Vitaliano (2012), por sua vez, elucidam em seu trabalho os principais saberes necessários para a promoção da Educação Inclusiva da perspectiva dos professores, com base em dados obtidos através de levantamento bibliográfico. Os saberes citados envolvem conhecer as barreiras sociais que dificultam o processo dos alunos com deficiência, os procedimentos didático-pedagógicos, a legislação, bem como as pesquisas e relatos que abordam processos inclusivos e requer, ainda, o conhecimento efetivo sobre 0 papel da Educação Especial na Educação Inclusiva. No entanto, sabe-se que, na realidade, nem sempre o Projeto Político Pedagógico das escolas e outros documentos relacionados, contemplam diretivas que viabilizam a realização dessas ações.

Continuando a linha de citações de empecilhos para a efetivação dessa metodologia citados na literatura, aqui os três primeiros problemas foram abordados por Mncube e Lebopa (2019):

- Formação do docente;

- Plano de ensino;

- Infraestrutura;

- Acompanhamento;

- Tempo, auxílio e número.

A prática da Educação Inclusiva é um processo relevante e necessário para o público ao qual deve atender, e não deve se limitar à integração desses alunos, pois essa ideia de esforço unilateral em que os alunos têm que se adaptar a um ambiente não preparado para eles, não condiz com o que é esperado de uma instituição de ensino inserida em uma sociedade democrática e justa, e não pode mais ser tolerada. Agora, é necessário prezar por uma eficiente inclusão desses grupos no contexto escolar, desenvolvendo ferramentas de aprendizagem eficientes.

\section{Gestão da qualidade em instituições de ensino}

Nas últimas décadas, os sistemas de informações e de tecnologias tiveram grandes mudanças no quesito de inovação. Devido ao aumento da demanda no mercado por 
http://dx.doi.org/10.5902/1984686X65753

pessoas altamente qualificadas para manusear tais equipamentos, e até mesmo desenvolver novos meios, houve a necessidade de aperfeiçoar o Sistema de Educação, principalmente quando se fala em qualidade no ensino, para assegurar que a nova geração possa acompanhar e progredirnesse avanço.

Sob a ótica do desafio da Educação Inclusiva, de acordo com Neto et al. (2018), causa preocupação o fato de muitas escolas não conseguirem, até o presente momento, assegurar a educação de qualidade, bem como perpetuarem uma prática que é mais excludente do que inclusiva. Atingir a excelência no ensino é, hoje, um grande desafio, e as escolas precisam desenvolver estratégias diferentes do que tem sido oferecido atualmente para que alcancem tal objetivo.

Logo, o Sistema de Gestão da Qualidade (SGQ) surge como uma opção eficiente nesse contexto. Vale ressaltar que, o SGQ vem sendo aplicado tanto em instituições de ensino básico como superior, e, como exemplos dessa ação se têm as províncias da China que adotam o SGQ nas pré-escolas (HU e LI, 2012) e na Universidade de Nairobi (MOTURI e MBITHI, 2015). E ainda é valido citar que algumas instituições de ensino aplicam a ISO 9001 para alcançar a melhoria contínua dos seus processos.

Medidas devem ser adotadas para obter um bom resultado ao implantar um Sistema de Gestão da Qualidade (RODRÍGUEZ-MANTILLA; FERNÁNDEZ-CRUZ; FERNÁNDEZDÍAZ, 2019). A principal medida adotada pelas Instituições de Ensino (IE), é o envolvimento total da gerência, e esse engajamento diz respeito à disponibilização de infraestrutura e meios para os professores que ali estão para poderem implantar esse Sistema. Os mesmos autores mencionam as alterações planejadas e estáveis no decorrer do tempo, para propor uma cultura organizacional com ênfase no clima da IE; esse clima pode ser entendido como estreitar os laços com os docentes, alunos e familiares, além da alta participação dos gestores, assim pondo em prática o objetivo do SGQ.

\section{Alinhamento entre os temas Gestão da Qualidade e Educação Inclusiva}

A decisão de implementar a prática de Gestão da Qualidade deve fazer parte do planejamento estratégico da instituição de ensino. Convém que a organização educacional estabeleça métodos de avaliações e medições, como, por exemplo, monitorar, estabelecer e documentar os indicadores de satisfação dos clientes, nesse contexto, alunos e familiares dos alunos. 
http://dx.doi.org/10.5902/1984686X65753

A falta de comprometimento da alta gerência é considerada uma importante barreira para a implementação de um SGQ (MOKHTAR et al., 2013; MCLEAN e ANTONY, 2014; TAYLOR e WRIGHT, 2003). E, quando se leva em consideração os elementos que envolvem a Educação Inclusiva, as dificuldades aumentam nesse contexto.

Sendo assim, a Gestão da Qualidade vem para apoiar e dar suporte no processo de acolhimento de todos os alunos nas instituições de ensino, sem restrição. Logo, temas como Gestão da Qualidade com base na NBR ISO 21001 e Lei Brasileira de Inclusão (LBI), são detalhados e colocados em paralelo.

\section{NBR ISO 21001}

A ABNT NBR ISO 21001 Organizações Educacionais - Sistema de Gestão para Organizações Educacionais - Requisitos com Orientação para Uso, foi aprovada no ano de 2020, e é a versão atualizada da última versão que foi homologada em 2006, a NBR ISO 15419 - Sistema de Gestão da Qualidade - Diretrizes para a aplicação da ISO 9001 em Organizações Educacionais.

Essa norma é parcialmente alinhada com a ISO 9001:2015 - Sistemas de gestão da qualidade - Requisitos, e tem por objetivo descrever os processos que as organizações adotam para que possam atender às necessidades dos alunos e outros beneficiários da organização, e especifica os requisitos para um Sistema de Gestão para Organizações Educacionais (SGOE), quando essa organização necessitar demonstrar a sua capacidade de apoiar a aquisição e o desenvolvimento de competências por meio de ensino, aprendizagem ou pesquisa, visando a aumentar a satisfação dos alunos, empregados e outros beneficiários (ABNT, 2020).

A norma lista quais serão os possíveis benefícios ao ser implantado um sistema de gestão nas organizações educacionais, e são eles:

I. Melhor alinhamento dos objetivos e atividades com a política;

II. Maior responsabilidade social, proporcionando educação de qualidade inclusiva e equitativa para todos;

III. Aprendizagem mais personalizada e resposta eficaz a todos os alunos e, em particular, aos alunos com necessidades educativas especiais, alunos a distância e oportunidades de aprendizagem ao longo da vida;

IV. Processos consistentes e ferramentas de avaliação para demonstrar e aumentar a eficácia e a eficiência; 
V. Maior credibilidade da organização;

VI. Um meio que permita às organizações educacionais demonstrar seu compromisso com práticas eficazes de gestão educacional;

VII. Uma cultura para melhoria organizacional;

VIII. Harmonização de normas regionais, nacionais, abertas, proprietárias e outras normas dentro de uma estrutura internacional;

IX. Participação ampliada dos interessados;

X. Estímulo à excelência e inovação.

A referida norma segue outros padrões de sistemas de gestão ISO e adota o ciclo PDCA (Plan-Do-Check-Act), para que a organização alcance os seus objetivos de acordo com suas políticas adotadas, liderança e responsabilidade social, entendendo seu contexto e levando em consideração a mentalidade de risco, conforme figura 1.

Figura 1 - Representação esquemática do ciclo PDCA no SGOE

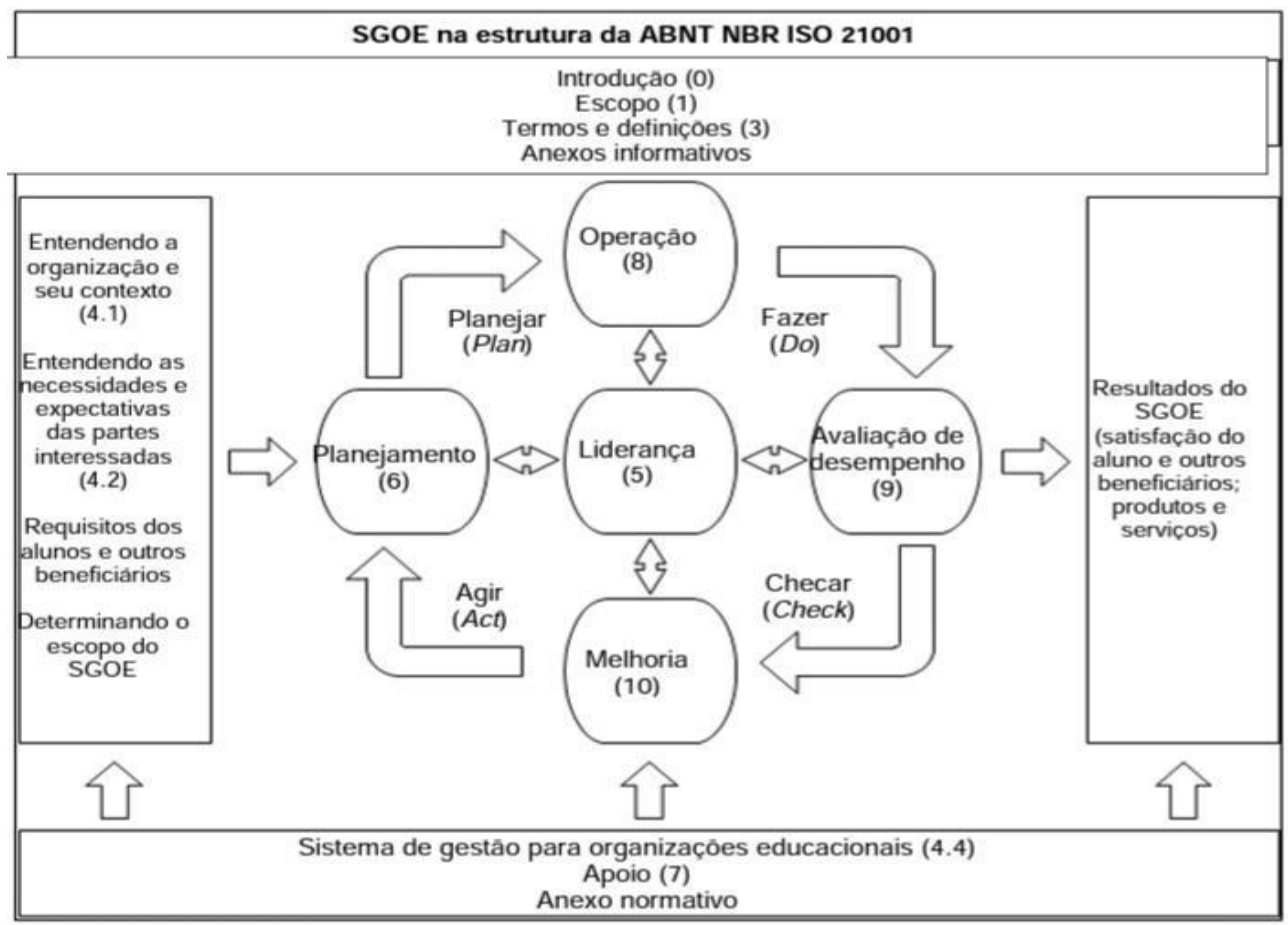

Fonte: Norma NBR ISO 21001 (2020).

No quesito de mentalidade de risco, a NBR ISO 21001 diz respeito à capacidade da organização em planejar e incorporar medidas para os riscos e oportunidades. Esses últimos proporcionam ao Sistema de Gestão das Organizações Educacionais (SGOE), uma forte base para a eficiência e eficácia da gestão da qualidade, consequentemente, podem lidar com situações negativas. 


\section{Comparativo entre a NBR ISO 21001 e a Lei Brasileira de Inclusão}

Com base no alinhamento destes dois temas (Gestão da Qualidade e Educação Inclusiva), foi realizada uma análise comparativa entre a Lei Brasileira de Inclusão (LBI) de julho de 2015, mais precisamente o capítulo IV (Do direito à educação), e a ISO 21001. Nesse sentido, é possível traçar um paralelo ressaltando os pontos em comum de acordo com a Tabela 1:

Tabela 1 - Comparativo entre a LBI e a NBR ISO 21001

\begin{tabular}{|c|c|}
\hline LBI & NBR ISO 21001 \\
\hline $\begin{array}{l}\text { Projetos pedagógicos para atender às } \\
\text { necessidades dos estudantes. }\end{array}$ & $\begin{array}{l}\text { Emprego de estratégias de instrução } \\
\text { diferenciadas que são direcionadas para os alunos } \\
\text { na sala de aula. }\end{array}$ \\
\hline $\begin{array}{l}\text { Participação dos estudantes com deficiência } \\
\text { e de suas famílias nas diversas instâncias de } \\
\text { atuação da comunidade escolar. }\end{array}$ & $\begin{array}{l}\text { Manter a comunicação e fazer o relacionamento } \\
\text { entre alunos, professores, familiares e funcionários } \\
\text { para as diversas atividades }\end{array}$ \\
\hline $\begin{array}{l}\text { Formação e disponibilização de professores } \\
\text { para o atendimento dos alunos com } \\
\text { deficiência. }\end{array}$ & $\begin{array}{l}\text { Assegurar que todos os educadores e empregados } \\
\text { que tenham contato com alunos com deficiência } \\
\text { tenham treinamento especializado apropriado. }\end{array}$ \\
\hline $\begin{array}{l}\text { Acesso à educação superior e à educação } \\
\text { profissional e tecnológica em igualdade de } \\
\text { oportunidade e condições com as demais } \\
\text { pessoas. }\end{array}$ & $\begin{array}{l}\text { Organizações bem-sucedidas são inclusivas, } \\
\text { flexíveis, transparentes e responsáveis, com o } \\
\text { objetivo de atender às necessidades, interesses, } \\
\text { habilidades e origens individuais dos alunos. }\end{array}$ \\
\hline $\begin{array}{l}\text { Melhoria dos sistemas educacionais para } \\
\text { melhor acesso, participação, aprendizado, } \\
\text { entre outros. }\end{array}$ & $\begin{array}{l}\text { A organização deve determinar e selecionar } \\
\text { quaisquer ações necessárias para atender aos } \\
\text { requisitos do aluno e de outros beneficiários e } \\
\text { aumentar a satisfação dos alunos }\end{array}$ \\
\hline Oferta de profissionais de apoio escolar & $\begin{array}{l}\text { Assegurar que essas pessoas sejam competentes, } \\
\text { baseado em educação, treinamento ou experiência } \\
\text { apropriada. }\end{array}$ \\
\hline $\begin{array}{l}\text { Acesso da pessoa com deficiência em } \\
\text { igualdade de condições, a jogos e atividades } \\
\text { recreativas, esportivas e lazer, no sistema } \\
\text { escolar. }\end{array}$ & $\begin{array}{l}\text { Oferecer acomodação adequada para os alunos } \\
\text { com deficiência para promover o acesso equitativo } \\
\text { às instalações e aos ambientes educacionais, } \\
\text { como outros alunos. }\end{array}$ \\
\hline $\begin{array}{l}\text { Disponibilizar recursos de acessibilidade e } \\
\text { de tecnologia assistida. }\end{array}$ & $\begin{array}{l}\text { A organização deve prover recursos de } \\
\text { aprendizagem, conforme apropriado, e deve } \\
\text { disponibilizá-los onde e quando necessário. }\end{array}$ \\
\hline $\begin{array}{l}\text { Disponibilização de formulários com campos } \\
\text { específicos para serem preenchidos e } \\
\text { informados os tipos de recursos necessários } \\
\text { para atender suas necessidades. }\end{array}$ & $\begin{array}{l}\text { A organização deve ter em conta as necessidades } \\
\text { dos alunos com deficiência e deve assegurar que } \\
\text { uma variedade de requisitos de acessibilidade seja } \\
\text { antecipada. }\end{array}$ \\
\hline $\begin{array}{l}\text { Disponibilizar provas acessíveis a suas } \\
\text { necessidades. }\end{array}$ & $\begin{array}{l}\text { Sejam definidos todos os recursos necessários } \\
\text { para completar com sucesso as atividades de } \\
\text { aprendizagem. }\end{array}$ \\
\hline
\end{tabular}

Fonte: Os autores (2021). 
Esses dois elementos apresentados na tabela 1 podem ser trabalhados de forma conjunta em prol da qualidade do ensino e da gestão educacional em instituições que possuam alunos com algum tipo de deficiência. A tabela mostra a importância do trabalho integrado de normas e leis.

\section{Proposição de um modelo de SGQ em instituições de ensino sob o enfoque da Educação Inclusiva}

Esse modelo proposto pode ser implantado em qualquer instituição de ensino com o enfoque da Educação Inclusiva conforme Figura 2. O referido modelo, contempla importantes elementos que precisam ser trabalhados conjuntamente. Esses elementos darão suporte a cinco diretrizes apresentadas posteriormente. Para ilustrar como será fundamentado esse modelo, segue o esquema na figura 2 abaixo:

Figura 2 - Representação esquemática do modelo proposto

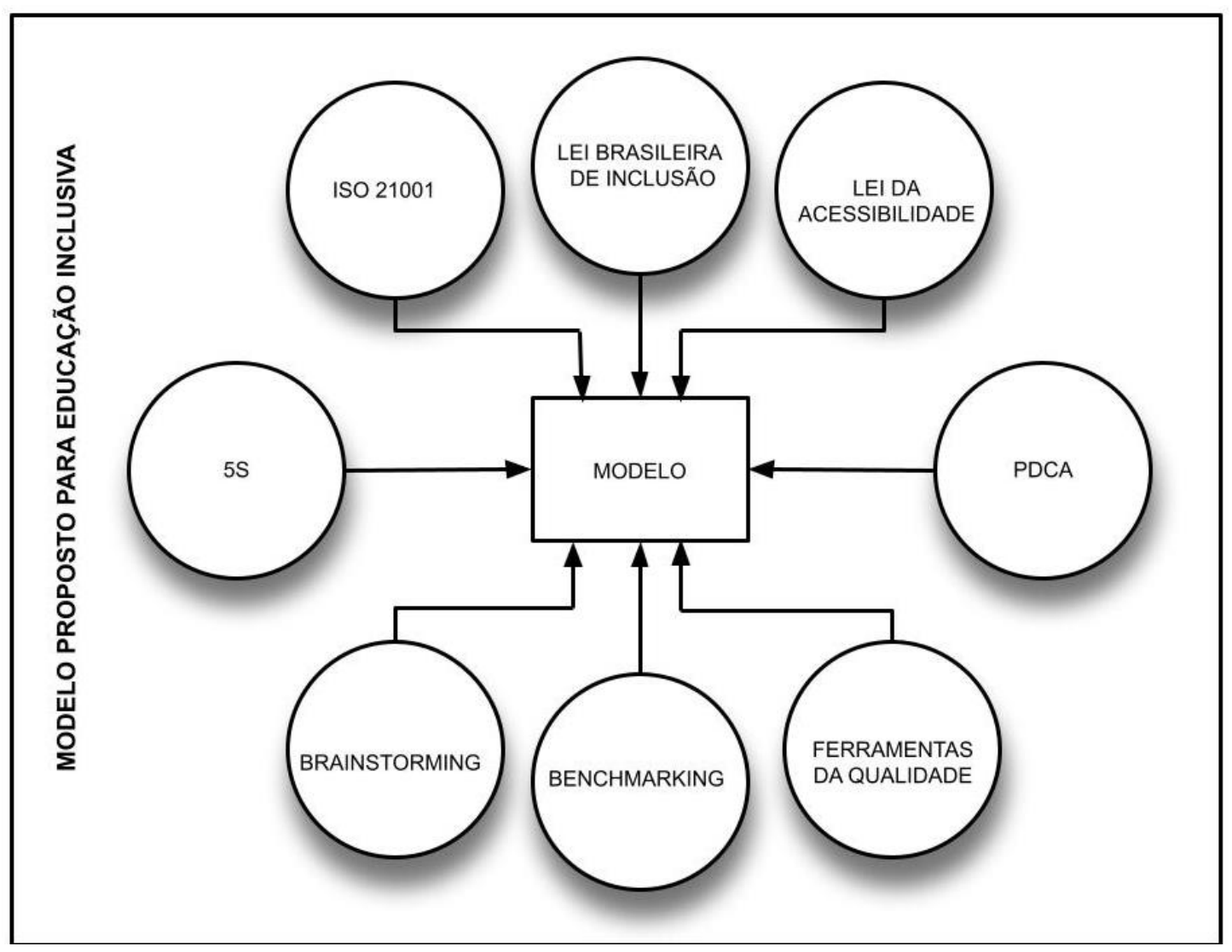

Fonte: Os autores (2021).

Como visto, esse modelo é composto por dois aspectos: o primeiro é trabalhado de acordo com as normas e leis para garantir o bem-estar e acessibilidade dos alunos com 
http://dx.doi.org/10.5902/1984686X65753

algum tipo de deficiência. Na segunda, são levadas em conta algumas ferramentas que irão sustentar a boa prática da Educação Inclusiva para garantir a fluidez das ações. Sendo assim, o modelo aparenta ser complexo, mas o seu objetivo principal é integrar as leis e a gestão da qualidade com a finalidade de sustentar a prática da educação inclusiva. Assim, seguem as diretrizes que compõem o modelo proposto, com base em revisão bibliográfica, análise de normas e leis, e entrevista com um especialista na área educacional. São elas:

\section{Suporte à acessibilidade}

Essa ação consiste em medidas que possuem grandes impactos. Focar atenção nas rampas, corrimões, piso tátil, banheiros adaptados, mobiliárias adaptadas (cadeiras adaptadas) e piso antiderrapante. Esses elementos auxiliarão essas pessoas a transitarem ao longo de toda instituição sem haver barreiras físicas de acesso.

\section{Envolvimento da instituição}

Segundo Weckenmann, Akkasoglu e Werner (2015), os conceitos de Gestão da Qualidade hoje em dia são usados também em áreas sem competição direta, com uma necessidade de melhoria própria, como as áreas de educação, saúde ou administração pública. Logo, o comprometimento dos colaboradores possui um papel cada vez mais importante.

Quando se refere ao envolvimento da instituição, deve-se considerar a alta gerência, professores, funcionários, alunos e os próprios familiares. Nessa etapa, todos poderão trabalhar para um bem comum, assim, técnicas de qualidade, como o Brainstorming e Benchmarking, serão uteis.

De acordo com Rodrigues (2014), Brainstorming é uma técnica para estimular a geração ou criação de ideias por um grupo de pessoas em um curto intervalo de tempo. Ela é multidisciplinar, criativa, inovadora e ousada. Segundo Peinado e Groeml (2007), essa técnica pode ter seu nome literalmente traduzido como "tempestade de ideias".

Conforme Spendolini (1992), já o Becnhmarking é um processo contínuo e sistemático para avaliar produtos, processos de trabalho de organizações reconhecidas como representantes das melhores práticas organizacionais. No contexto do trabalho, são comparações entre organizações educacionais com a finalidade de identificar quais as melhores práticas adotadas e utilizá-las como referência. 
http://dx.doi.org/10.5902/1984686X65753

\section{Capacitação adequada e auxílio}

Os profissionais que irão trabalhar diretamente com os alunos, deverão possuir qualificação para poder atender as necessidades de cada estudante dentro e fora da sala de aula. Essa qualificação pode ser entendida como cursos específicos nas áreas de inclusão, a própria grade curricular da formação, a experiência profissional e sempre a busca por novos conhecimentos, assim alcançando a melhoria contínua e a competência que a NBR ISO 21001 aborda.

Deve ser levado em consideração, também, o papel do Gestor de Educação Inclusiva nesse cenário. As responsabilidades desse profissional envolverão a gestão de todos os esforços voltados à inclusão, o acompanhamento de profissionais de apoio e o gerenciamento dos recursos necessários para esse suporte. O profissional deve ter essas atribuições, ficando a critério da escola a escolha do termo para nomear essa função, uma vez que o termo citado é meramente uma sugestão de denominação.

Também é importante lembrar que nem sempre um único professor para lidar com mais de um aluno com deficiência na sala de aula é suficiente. Assim, caberá à instituição disponibilizar professores auxiliares para ajudar na sala de aula. Nesse contexto, pode até ser desenvolvido um projeto de residência para professores em formação, com isso será mais fácil a captação de auxiliares.

\section{Avaliação dos alunos}

Levar em consideração as várias possibilidades de avaliação escolar do aluno, como avaliações alternativas com acessibilidade metodológica, e não só focar nos modelos tradicionais (como provas, por exemplo).

\section{Planejamento periódico}

A utilização da metodologia dos $5 \mathrm{~S}$ ( 5 sensos) vem para mudar a filosofia das pessoas que ali estão presentes, e ajudar no comprometimento do projeto. Segundo Osada (1992), esta técnica é definida a partir de cinco palavras japonesas: Seiri, Seiton, Seiso, Seiketsu e Shisuke. Em tradução direta para o português, essas palavras possuem os respectivos significados: Utilização/Organização, Arrumação/Ordenamento, Limpeza, Padronização e Disciplina. Para Ballestero-Alvarez (2019), o 5S constitui um processo educacional que visa promover a mudança comportamental das pessoas a partir da práticas participativas e do 
conhecimento das informações, mudança comportamental voltada à melhoria contínua da qualidade

$\mathrm{Na}$ instituição pode ser aplicado esse programa, fortificando principalmente os sensos de utilização, organização e disciplina. Essa metodologia necessita de que os indivíduos inseridos no meio estejam envolvidos nessa prática, pois serão a chave primária para a mudança. Esses sensos darão suporte para planejamento, seleção de materiais, prioridades e melhor cultura educacional.

Outro fator importante para ajudar no planejamento e a traçar metas para a organização, é o ciclo PDCA (Planejar - Fazer - Checar - Agir), muito difundido para melhoria contínua. Segundo Garvin (1988), Walter A. Shewhart desenvolvou o ciclo PDCA, que foi lapidado e difundido em conjunto com W. Edward Deming. Essa técnica consiste em seguir um passo a passo em forma cíclica. De acordo com a NBR ISO ISO 21001:2020, o ciclo PDCA pode ser aplicado para todos os processos e para o Sistema de Gestão das Organizações Educacionais (SGOE).

Assim, a instituição sempre estará executando os seus planos, verificando e agindo a fim de solucionar a causa raiz e efetivar a Educação Inclusiva. A viabilização das diretrizes propostas, pode trazer, além de um Sistema de Gestão Educacional adequado a todos os alunos, profissionais específicos e prontos para atender às demandas de alunos com deficiência e promover uma economia de recursos. Essa economia será percebida, uma vez que a instituição de ensino estará preparada e seguirá com as adaptações para os referidos alunos de forma fluida, eficiente e eficaz.

\section{Conclusão}

A partir do exposto, percebe-se que através do levantamento bibliográfico foi possível verificar a existência de diversas convenções e ações normativas que se destinam ao público dos estudantes com deficiência. Essas têm por objetivo a inserção e permanência desses estudantes nas classes comuns de escolas regulares dos sistemas de ensino. As organizações educacionais devem oferecer apoio pedagógico para que esses alunos tenham suas necessidades educativas atendidas, e para que possam progredir nos níveis de ensino durante a sua permanência na IE. Para a promoção de condições de acesso e permanência igualitárias, a IE precisa de organização e de novas abordagens gerenciais que possibilitem o alcance desses objetivos. O SGQ surge para dar suporte e garantir a 
preparação da IE nesse processo. No entanto, ainda se percebe que existem entraves à prática efetiva da Gestão da Qualidade no contexto da Educação Inclusiva.

De fato, a Gestão da Qualidade vem sendo aplicada nas Instituições de Ensino, prática recente no Brasil (SANTANA; NUNES, 2018), tanto nas pré-escolas quanto nas instituições de ensino superior. Para concretizá-la, é de extrema importância que haja um modelo ou diretrizes a serem seguidas e que possam sustentar essa prática, que, por muitas vezes, são iniciadas e não são finalizadas, justamente por não haver ações sequenciais para consolidar essa filosofia educacional.

Devido às dificuldades encontradas na implantação de um sistema de gestão da qualidade no contexto inclusivo, mesmo seguindo as normas e leis que auxiliam na prática, o modelo proposto no presente artigo visa a uma abordagem diferente para sustentar a Educação Inclusiva. Consiste na integração entre o sistema de Gestão da Qualidade e as normas e leis sobre a Educação Inclusiva, principalmente a NBR ISO 21001: 2020. Dessa maneira, as diretrizes poderão facilitar nos processos internos da organização, seja por ganho de velocidade na resolução de possíveis problemas, seja por um maior entendimento do sistema que ali está presente. Esse modelo foi elaborado pensando também nos principais entraves que foram levantados na literatura, facilitando, assim, a implantação da educação inclusiva e garantindo a permanência dos estudantes.

\section{Referências}

AMOR, Antonio Manuel. et al. International perspectives and trends in research on inclusive education: a systematic review. International Journal of Inclusive Education. Kansas, v. 23, n.12, p.1277-1295, 2018.

BALLESTERO-ALVAREZ, María Esmeralda. Gestão da Qualidade, Produção e Operações. 3ed. São Paulo: Atlas, 2019.

ABNT. Associação Brasileira de Normas Técnicas. NBR ISO 15419:2006 -Diretrizes para Aplicação da ABNT NBR ISO 9001:2000 nas Organizações Educacionais. Rio de Janeiro, 2006.

ABNT. Associação Brasileira de Normas Técnicas. NBR ISO 9001:2015-Sistema de Gestão da Qualidade - Requisitos. Rio de Janeiro, 2015.

ABNT. Associação Brasileira de Normas Técnicas. NBR ISO 21001:2020-Organizações Educacionais - Sistemas de Gestão para Organizações Educacionais - Requisitos com Orientações para Uso. Rio de Janeiro, 2020. 
http://dx.doi.org/10.5902/1984686X65753

BRASIL. Lei no 9.394 , de 20 de dezembro de 1996. Estabelece as Diretrizes e Bases da Educação Nacional. Diário Oficial [da] República Federativa do Brasil, Brasília, 20 dez.1996. Disponivel em: http://www.planalto.gov.br/ccivil_03/LEIS/L9394.htm Acesso em 17 dez. 2019.

BRASIL. Lei no 13.146, de 6 de julho de 2015. Estatuto da Pessoa com Deficiência. Diário Oficial [da] República Federativa do Brasil, Brasília, 6 jul. 2015. Disponível em: http://www.planalto.gov.br/ccivil_03/_ato2015-2018/2015/lei//13146.htm Acesso em 16 dez.2019.

BRASIL. Ministério da Educação - MEC. Secretaria de Educação Especial. Política Nacional de Educação Especial na Perspectiva da Educação Inclusiva. Brasília: MEC/ SEESP, 2008. Disponível em:

http://portal.mec.gov.br/arquivos/pdf/politicaeducespecial.pdf. Acesso em 15 set. 2021.

BRASIL. Decreto no 10.502, de 30 de setembro de 2020. Institui a Política Nacional de Educação Especial: Equitativa, Inclusiva e com Aprendizado ao Longo da Vida. Diário Oficial [da] República Federativa do Brasil. Brasília, 30 set. 2020. Disponível em: https://www.in.gov.br/en/web/dou/-/decreto-n-10.502-de-30-de-setembro-de-2020280529948. Acesso em 15 set. 2021.

FANTACINI, Renata Andrea Fernandes; ALMEIDA, Maria Amelia. Revisão Sistemática sobre a presença de Núcleos de Acessibilidade na Educação Superior EaD-2005 a 2018. Revista Educação Especial. Santa Maria, v.32, set. 2019. Disponível em: https://periodicos.ufsm.br/educacaoespecial/article/view/36305/36305. Acesso em 28 mar. 2021.

FERGUSON, Dianne. International trends in inclusive education: the continuing challenge to teach each one and everyone. European Journal of Special Needs Education. Philadelphia, v.23,n.2,p.109-120, 2008.

GARVIN, David. Managing Quality: The Strategic and Competitive Edge. Simon and Schuster, 1988.

GLAT, Rosana. et al. Formação de professores na Educação Inclusiva: Diretrizes políticas e resultados de pesquisas. In: ENDIPE - ENCONTRO NACIONAL DE DIDÁTICA E PRÁTICA DE ENSINO, XIII., 2006, Recife/PE. Anais... Recife: Universidade Federal de Pernambuco, 2006. vol. Único.

$\mathrm{HU}, \mathrm{Bi}$ Ying; LI, Kejian. The quality rating system of Chinese preschool education: prospects \& challenges. Childhood Education, Hangzhou, v.88, n.1, p.14-22,2012.

INEP. Instituto Nacional de Estudos e Pesquisas Educacionais Anísio Teixeira - Censo da Educação Básica 2019: Resumo Técnico. Brasília, 2020. Disponível em: https://download.inep.gov.br/publicacoes/institucionais/estatisticas_e_indicadores/resumo _tecnico_censo_da_educacao_basica_2019.pdf Acesso em: 30 mar. 2021.

MCLEAN, Richard; ANTONY, Jiju. Why continuous improvement initiatives fail in manufacturing environments? A systematic review of the evidence. International Journal of Productivity and Performance Management, v. 63, n. 3, p. 370-376. 2014. 
MENDONÇA, Ana Abadia dos Santos. Educação Inclusiva: Barreiras e Desafios. Revista Encontro de Pesquisa em Educação. Uberaba, v.1, n.1, p.4-16, 2013.

MNCUBE, Vusi; LEBOPA, Nicholas. The Dynamics of Implemeting Inclusive Education in Schools. Global Education in Practice: Teaching, Researching and Citizenship. Bulgaria, v.17, p. 146-512, 2019.

MOKHTAR, Sany Sanuri Mohd. et al. Sustaining a quality management system: process, issues and challenges. Business Strategy Series. Vol. 14 Issue: 4, pp.123-130. 2013.

MOTURI, Christopher; MBITHI, Peter. ISO 9001:2008 implementation and impacto on the University of Nairobi: a case study. The TQM journal. Nairobi, v.27, n.6, p. 752-760, 2015.

NETO, Antenor de Oliveira Silva. et al. Educação inclusiva: uma escola para todos.

Revista Educação Especial. Santa Maria, v.3, n.60, p.81-92, jan./mar. 2018. Disponível em: https://periodicos.ufsm.br/educacaoespecial/article/view/24091. Acesso em 27 mar. 2021.

NOZI, Gislaine Semcovici; VITALIANO, Celia Regina. Saberes necessários aos professores para promover a inclusão de alunos com necessidades Educacionais Especiais. Revista Educação Especial. Santa Maria, v.25, n. 43, maio/ago. 2012, p. 333348. Disponível em: https://periodicos.ufsm.br/educacaoespecial/article/view/3343/3824. Acesso em 28 mar. 2021.

OSADA, Takashi. Housekeeping, 5S's: seiri, seiton, seiso, seiketsu, shitsuke. São Paulo: Instituto IMAM, 1992.

PEINADO, Jurandir; GRAEML, Alexandre Reis. Administração da produção: operações industriais e de serviços. Curitiba: UnicemP, 2007.

RODRIGUES, Marcos Vinicios. Ações para a Qualidade: gestão estratégica e integrada para a melhoria dos processos na busca da qualidade e competitividade. 5. ed. - Rio de Janeiro: Elsevier, 2014.

RODRÍGUEZ-MANTILLA, Jesús Miguel; FERNÁNDEZ-CRUZ, Francisco José; FERNÁNDEZ-DÍAZ, Maria José. Comparative analysis between management team and teachers on the impact of ISO 9001 standards in educational centers. International of Quality and Service Science. Madrid, v.11, n.2, p. 248-264, 2019.

SANTANA, Iolamárcia; NUNES, Isabel. Educação especial e inclusão: As políticas públicas brasileiras de inclusão de pessoas público-alvo de educação especial em salas regulares. Revista eletrônica da FAINOR. Vitória da Conquista, v.11, n.3, p. 541$560,2018$.

SILVA, Francisca Marly Moreira da. et al. Abordagem História da Educação Especial no Brasil. ID on line Revista Multidisciplinar e de Psicologia, v.13, n.45, p.262-275, [S.I.], 2019.

SPENDOLINI, Michael J. Benchmarking. São Paulo: Makron Books, 1993. 
TAYLOR, W. Andrew; WRIGHT, Gillian H. A longitudinal study of TQM implementation: factors influencing success and failure. Omega, Elsevier, vol. 31(2), pages 97-111, Abril. 2003.

UNESCO. Educação Inclusiva no Brasil. Disponível em:

http://www.unesco.org/new/pt/brasilia/education/inclusive-education/ Acesso em: $16 \mathrm{dez}$. 2019.

URBAN, Ana Lidia Penteado. Um estudo de produções científicas: ingresso e permanência de universitários com deficiência. 2016. 130f. Dissertação (Mestrado em Educação) - Universidade Estadual Paulista "Júlio de Mesquita Filho" (Unesp), Faculdade de Ciências e Letras, Araraquara, 2016.

WECKENMANN, Albert; AKKASOGLU, Goeklan; WERNER, Teresa. Quality management history and trends. The TQM Journal, v. 27, n. 3. Issue: 3, pp.281-293, [S.I.], 2015.

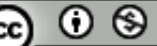

This work is licensed under a Creative Commons Attribution-NonCommercial 4.0 International (CC BY-NC 4.0) 